\title{
ARGUMENTAÇÃO EM DISCUROS ESCRITOS EM LÍNGUA PORTUGUESA COMO L2 POR PROFESSORES SURDOS USUÁRIOS DE LIBRAS
}

\author{
Gilton Sampaio de Souza é professor na área de Linguística, com ênfase nos estudos da argumentação, com atuação na graduação e \\ na pós-graduação (Mestrado e Doutorado) em Letras da Universidade do Estado do Rio Grande do Norte. E-mail: \\ giltonssouza@gmail.com
}

Mara Rúbia Pereira dos Santos é mestranda em Letras pela Universidade do Estado do Rio Grande do Norte e professora de Língua Portuguesa na Educação Básica.

E-mail: mararubiaenzo.jp@ gmail.com

Aluizio Lendl é mestrando em Letras pela Universidade do Estado do Rio Grande do Norte e professor na área de Linguística na Universidade Regional do Cariri.

E-mail: lendl.b3@gmail.com

\section{Resumo}

Este trabalho tem como objetivo interpretar a argumentação em Língua Portuguesa como segunda língua, em discursos de sujeitos surdos, usuários de LIBRAS. O corpus é constituído por respostas dadas a questionários. A base teórica é a Nova Retórica e os discursos analisados revelaram que surdos utilizaram de argumentação predominantemente baseada na estrutura do real, especialmente em casos particulares.

\begin{abstract}
This work aims to interpret the arguments in Portuguese as a Second Language in deaf subjects speeches, LIBRAS users. The corpus consists of responses given to a questionnaires. The Theoretical base and the New Rhetoric and the Discourses analyzed revealed that deaf used predominantly of argument based on the actual structure, especially in particular case
\end{abstract}

\section{1) Introdução}

O presente trabalho é fruto de reflexões e questionamentos acerca da atividade argumentativa desenvolvida em Língua Portuguesa por surdos bilíngues, usuários da Língua Brasileira de Sinais (LIBRAS). Esse se tornou nosso foco de estudo por diversos motivos, dentre os quais podemos destacar nosso interesse em constatar de que forma se estrutura a argumentação no discurso dos surdos bilíngues, a partir dos pressupostos teóricos da Nova Retórica.

Justificamos a pertinência deste trabalho pela contribuição para o desenvolvimento de intervenções educacionais inclusivas tendo em vista a necessidade de haver um diálogo entre as línguas (Língua Portuguesa escrita e LIBRAS) na relação dos surdos com a linguagem, cujo diálogo precisa ser enfatizado por pesquisas das mais diversas áreas.

Ainda é pertinente destacar a importância deste estudo por representar continuidade a outros já realizados na área da argumentação no discurso, desenvolvidos pelo Grupo de Pesquisa em Produção e Ensino de Texto (GPET), da Universidade do Estado Rio Grande do Norte (UERN), Campus Pau dos Ferros, mais precisamente os da 
linha de pesquisa em "Estudos de processos argumentativos". Entre vários estudos realizados, podemos destacar Souza (2001, 2003); Souza, Costa e Filgueira (2012); dentre outros. $\mathrm{O}$ aporte teórico para os estudos realizados no grupo advém principalmente dos pressupostos teóricos da Nova Retórica ou Teoria da Argumentação (PERELMAN, OLBRECHTS-TYTECA, 2005), como também de outros estudos realizados na área, como Reboul (2004), Fiorin (2012) e Plantin (2008).

Trazemos, portanto, neste artigo a proposta de análise da argumentação em discursos de usuários de Língua Portuguesa como segunda língua (L2). Portanto, o corpus desta pesquisa se constitui de discursos escritos em português como L2, que foram trazidos à análise por excertos retirados das entrevistas realizadas com dois professores formados, com nível superior, e usuários de LIBRAS, que residem e atuam em cidades e regiões diferentes do Estado do Rio Grande do Norte. As entrevistas foram aplicadas aos dois professores, participantes como colaboradores desta pesquisa, e seguiram as mesmas orientações teórico-metodológicas, com questionários escritos, abertos, os quais lhes foram enviados para que lessem e respondessem também por escrito, em português. Estruturamos este trabalho em seções e conta, na primeira seção, com reflexões acerca da linguagem, sobre o percurso histórico da linguagem dos surdos e ainda acepções acerca do bilinguismo. Em seguida, trazemos os conceitos sobre argumentação no discurso, com base na Nova Retórica, e as principais categorias teóricas que são focalizadas no trabalho. $\mathrm{Na}$ parte das análises, apresentamos a interpretação da argumentação em discursos escritos em português como L2, articulando-os com uma proposta teórico-metodológica de análise das teses e das técnicas argumentativas. Por fim, nas considerações finais, retomamos os objetivos pretendidos e os resultados alcançados.

\section{2) Linguagem, surdez, Língua Portuguesa e bilinguismo}

O uso efetivo de uma língua por uma ou diferentes comunidades de falantes é o que determina a vitalidade e abrangência da língua nas dimensões local, regional, nacional e em âmbito até mundial. Desse modo, quanto mais utilizada, mais prestígio social ela ganha e quanto menos houver essa utilização mais estará propensa a perder sua importância. Portanto, a identidade de uma língua está intrinsecamente ligada à identidade de seu povo. Podemos interligar a identidade linguística, a identidade nacional e a identidade de indivíduos aos direitos linguísticos e aos usos sociais da língua (BRASIL, 2004).

Nesse sentido, temos na constituição de identidade do indivíduo, na busca por seus direitos como cidadãos, a luta da comunidade surda pelo direito linguístico nas instituições escolares do país. No entanto, o que observamos é que no processo educativo, por ser influenciado por forças ideológicas externas à educação, percebemos que a sociedade ainda põe resistências e dificuldade em se acreditar na capacidade de aprendizagem dos indivíduos surdos. Por essa razão, é perceptível a negatividade 
construída em torno da surdez. Os espaços para estudos, atuação e interação dos surdos, nas escolas públicas e privadas, são pequenos e limitados em opções.

Embora, ao longo da história, tenhamos caminhado a pequenos passos no processo de inclusão dos surdos na sociedade brasileira, já é possível observar um significativo avanço do que fora outrora, conforme demonstrou Goldefeld (2002). Esse avanço teve seu marco inicial em 1855, com a chegada do professor surdo francês Hernest Huet, trazido pelo imperador D. Pedro II, com a finalidade de educar duas crianças surdas. A partir de então aconteceram as primeiras abordagens na língua dos surdos, pois antes disso eles viviam na obscuridade social. O referido professor utilizava uma metodologia que garantia a aprendizagem pelo surdo e, para tanto, fazia uso da Língua de Sinais. Esclarecemos, ainda, que Huet foi o patriarca da Língua Brasileira de Sinais e marcou positivamente os avanços na educação dos surdos brasileiros, porque ele fundou a primeira escola para surdos no Rio de Janeiro, Instituto Nacional de Educação de surdos - INES. Essa escola ainda existe no Rio de Janeiro, no bairro de Laranjeiras (MAZZOTA, 2003).

Ainda conforme Mazzota (2003), no ano de 1880, em Milão, realizou-se o II Congresso Internacional sobre Educação de Surdos. Este congresso foi o marco histórico de maior impacto na área da surdez e também um momento obscuro de toda essa jornada, pois desde aquele momento, a educação dos surdos teve sua continuação em sentido oposto à educação proposta no século XVII, quando os surdos e a sociedade em geral tinham percebido as potencialidades dos surdos pela utilização da língua de sinais. Nesse Congresso, foi realizada uma votação para eleger qual seria o método mais apropriado para a educação de surdos, se continuava com a utilização da língua de sinais como já vinha ocorrendo ou se partiriam para a utilização apenas da língua oral. O resultado foi que o Oralismo Puro (utilização apenas da língua oral) foi eleito como a melhor abordagem para os alunos surdos, culminando na proibição da utilização da língua de sinais nas escolas de surdos. O mais importante ícone do Oralismo foi Alexander Graham Bell (inventor do telefone), que exerceu a grande influência no resultado da votação do Congresso Internacional de Educadores de Surdos, realizado em Milão, no ano de 1880.

Depois de longos anos de obscuridade para a comunidade surda, com o uso exclusivo do Oralismo, a partir de 1979 Suzanne Boral-Maisong promoveu a primeira experiência pedagógica baseada no Bilinguismo na França, numa classe com duas professoras, uma ouvinte e uma surda, desde então fora retomado o ensino para surdos a partir da língua de sinais. Por conseguinte, baseando-se no trabalho de Suzanne, a professora Danielle Bouvet, em 1981, iniciou a sua primeira turma bilíngue (STUMPF, 2006), em que a língua de sinais francesa foi ensinada como língua materna dos surdos e

a língua francesa como segunda língua, conseguindo dessa forma mais abrangência a essa abordagem.

Esses marcos históricos ocorridos na França refletiram positivamente na luta dos surdos de todo o mundo em busca do bilinguismo no contexto escolar. Os surdos conquistaram o direto de serem bilíngues, tendo a língua de sinais como língua oficial da 
comunidade e a língua materna de seu país como segunda língua. Nessa perspectiva devemos considerar a importância desse fato devido ser

[...] uma proposta de ensino usada por escolas que se propõem a tornar acessível à criança duas línguas no contexto escolar. Os estudos têm apontado para essa proposta como sendo mais adequada para o ensino de crianças surdas, tendo em vista que considera a língua de sinais como língua natural e parte desse pressuposto para o ensino da língua escrita. (QUADROS, 1997, p. 27).

Ainda nessa perspectiva de articular a língua de sinais, como língua natural, ao ensino da língua escrita, como apontada por Quadros (1997), muitos estudos têm sido desenvolvidos para se analisarem como funciona a linguagem dos surdos na perspectiva de utilizar duas línguas. Na década de 1980, iniciou-se a implantação da filosofia bilíngue efetivamente e na década de 1990 essa abordagem começou a ter mais adeptos em todos os países do mundo, conforme apontou Goldfeld (2002). Nessa perspectiva, o surdo pode ser bilíngue, porque este tem condições de adquirir como língua materna a língua de sinais, que é considerada a língua natural dos surdos, e, como segunda língua (L2), a língua oficial do seu país, no caso do Brasil, o Português.

Um conceito importante vinculado a essa abordagem do bilinguismo para os surdos é que o sujeito surdo é dotado de uma língua de modalidade visuoespacial e possui uma cultura própria. Kozlowski (2000) defende, portanto, que a criança surda deve adquirir a língua de sinais assim como precisa ser alfabetiza na língua oficial de seu país, participando dessa forma de um ambiente bicultural.

A abordagem de línguas bilíngues para surdos, defendida por Kozlowski (2000) e Fernandes (2011), parte do pressuposto de que a educação para surdos deva acontecer, no Brasil, em duas línguas, como exposto a seguir: L1 - Língua Brasileira de Sinais (LIBRAS); e L2 - Língua Portuguesa, sendo a modalidade escrita desta ensinada obrigatoriamente e a modalidade oral, possivelmente, já que nem todos os surdos têm oportunidades de desenvolver a oralidade, como segunda língua. Nesse sentido, o Bilinguismo é uma proposta de ensino-aprendizagem de línguas (L1 e L2) usada por escolas que se propõem tornar acessível à criança surda duas línguas no contexto escolar. Preconiza-se a ampliação, no contexto escolar, da capacidade comunicativa e interacional dos indivíduos com surdez. Atualmente, essa é uma das abordagens de ensino de línguas para surdos com maior repercussão no Brasil, de acordo com Strobel (2008).

Assim, na década dos anos 1990, um projeto de Lei, da então senadora Benedita da Silva, deu início a uma longa batalha de legalização e regulamentação da LIBRAS, em âmbito federal, o que culminou com a criação da Lei n ${ }^{\circ} 10.436$ de 24 de abril de 2002 (BRASIL, 2004), que reconhece a Língua Brasileira de Sinais, seguida pelo Decreto $\mathrm{n}^{\circ}$ 5.626, de 22 de dezembro de 2005, que a regulamenta (BRASIL, 2004). Este Decreto contém nove capítulos dispondo sobre os seguintes temas: a LIBRAS como disciplina curricular; o ensino da Língua Portuguesa oferecido aos alunos surdos como segunda 
língua; a formação de profissionais bilíngues; e também a regulamentação do uso e da difusão dessa língua em ambientes públicos e privados.

Todas essas reflexões teórico-metodológicas e históricas, assim como essas regulamentações sobre o ensino de LIBRAS como disciplina curricular e de Língua Portuguesa como segunda língua no Brasil, para pessoas com surdez, trazem motivações a mais para o reconhecimento da pertinência do ensino-aprendizagem de português como L2 para sujeitos surdos, usuários de LIBRAS. Consequentemente, é necessário haver um estudo sobre como os surdos fazem uso da língua portuguesa em situações cotidianas e nos espaços escolares, como organizam suas ideias, seus pontos de vista; enfim, como interagem e argumentam em espaços sociais e públicos, dentro e fora dos espaços escolares, mediante o uso de português como L2, sendo esse também o foco principal desse artigo.

\section{3) Argumentação no discurso: aspectos conceituais}

A argumentação na língua e no discurso e a argumentação retórica em especial ocupam lugar de destaque nos estudos linguísticos e sociais na atualidade, baseados no pressuposto de que a argumentatividade é intrínseca à linguagem humana, é de sua natureza constitutiva. Na verdade, como destacam Fiorin (2005) e Perelman e OlbrechtsTyteca (2005), esses estudos são antigos e nos remetem à Antiguidade Grega, antes de Cristo.

A Retórica Antiga, nascida na Grécia entre os séculos V e IV a.C., tinha como principal finalidade usar a oratória em função do convencimento e da persuasão de um auditório, por isso os estudos antigos revelam que a Retórica grega estava intrinsecamente ligada a "arte do bem falar em público" (REBOUL, 2004). Foi somente a partir de Aristóteles que tivemos uma primeira reflexão sistemática e teórica sobre a oratória e as técnicas de persuasão. Aristóteles já havia pensado a argumentação como um componente dos sistemas lógico, retórico e dialético. Consideremos, nesse sentido, a lógica como a "arte de pensar corretamente", a retórica como "a arte de bem falar", e a dialética, "a arte de bem dialogar" como concepções que permeavam as reflexões e estudos retóricos e argumentativos desde sua gênese, sendo interligado nos estudos retóricos atuais. Essa tríade compõe a base do sistema no qual a argumentação fora estudada na época.

Durante um longo tempo, os estudos sobre argumentação retórica perderam força, em função, sobretudo, dos usos inadequados, ornamentais que dela fizeram durante alguns séculos. Segundo Plantin (2008), a retórica foi violentamente criticada como disciplina não científica e eliminada do currículo das universidades, sendo digna de estudo nesses ambientes apenas sua história.

No entanto, como destacam Reboul (2005) e outros estudiosos da argumentação (SOUZA, 2003, 2008; FIORIN, 2005; PERELMAN, OLBRESCSTS-TYTECA, 2005), com o avanço das sociedades democráticas e com a necessidade cada vez maior de se dar voz às diversas camadas da sociedade, pobres e ricos, letrados e analfabetos, surge, em 
todas as democracias, a urgência de se estudar a retórica, a arte de argumentar, como forma de se criarem mais elementos para convencer e persuadir os públicos a que se destinavam as comunicações, assim como de entender e interpretar de que forma as pessoas estavam convencendo as multidões e, em consequência dos bons discursos, vencendo disputas políticas, econômicas, religiosas, dentre outras.

Esses estudos estão bem avançados e ganharam mais força e consistência acadêmica e científica com lançamento do livro "Tratado da Argumentação: a Nova Retórica", em 1958, por Perelman e Olbrechts-Tyteca, cuja obra revigora os estudos retóricos e os levam para diferentes campos dos estudos da linguagem, nas modalidades orais e escritas, em diferentes campos da atividade humana, em usuários e falantes de línguas maternas e estrangeiras, de primeira e segunda línguas etc.

No ano de 1958, quando Perelman e Olbrechts-Tyteca publicam a primeira versão do Tratado de Argumentação, reavivam-se os estudos na área, além de propor novas abordagens que poderiam contribuir para os estudos, os usos e até o ensino da argumentação retórica nos espaços escolares e fora deles. Os autores apontam para uma retomada dos estudos aristotélicos sobre retórica, dando uma nova abordagem, mais argumentativa e contemporânea, tornando-a uma Nova Retórica.

O objeto da retórica antiga era, acima de tudo, a arte de falar em público de modo persuasivo; referia-se, pois, ao uso da linguagem falada no discurso, perante uma multidão reunida na praça pública, com o intuito de obter a adesão desta a uma tese que lhe apresentava. Vê-se, assim, que a meta da arte oratória - a adesão dos espíritos - é igual a de qualquer argumentação. Mas não temos razões para limitar nosso estudo à apresentação de uma argumentação oral e para limitar a uma multidão reunida numa praça o gênero de auditório ao qual nos dirigimos. (PERELMAN; OLBRECHTS-TYTECA, 2005, p. 6).

Assumindo a argumentação como assuntos pertinentes a todos os discursos e gêneros, orais e escritos, os autores redimensionam vários conceitos da retórica antiga e ampliam seu horizonte. O foco de Perelman e Olbrechts-Tyteca (2005), em seu Tratado da Argumentação, vai mais longe, apresentando-se também como uma crítica ao cartesianismo na linguagem e como um estudo vigoroso sobre a dialética da linguagem. O foco está centrado, portanto, na argumentação retórica do texto escrito (estendendo-o ao oral), preocupando-se com a orientação lógica, com a dialética e com estrutura da argumentação, com as técnicas discursivas e com outros elementos que constituem os processos argumentativos que subjazem qualquer discurso, de qualquer gênero e esfera da comunicação humana, sobre os quais faremos uma pequena síntese, priorizando as categorias teóricas que serão utilizadas na análise dos discursos dos professores surdos.

\section{1) Teses e técnicas argumentativas}

Para a efetivação do processo argumentativo, dá-se uma ação direcionada do orador no intuito de conquistar adesão do auditório, o seu consentimento. Quando se trata 
de influenciar, por meio do discurso, deve-se considerar a intensidade da adesão do auditório a certas teses (SOUZA, 2008).

Para tanto, o falante/escritor (que é também o orador na perspectiva dos estudos retóricos) deve pensar nos argumentos capazes de influenciar o seu interlocutor, o seu auditório, o público a quem se destina, a quem pretende convencer ou persuadir. Assim, devemos levar em consideração as teses defendidas, as técnicas argumentativas e os próprios argumentos que podem influenciar mais ou menos determinados auditórios.

Concebendo o discurso como uma ação orientada, intencional e simbólica do sujeito discursivo, como espaço e meio de realização dos processos argumentativos, de pontos de vista, de argumentos (PERELMAN, OLBRECHTS-TYTECA, 2005, p. 213), destacamos que é no discurso que se constrói a argumentatividade da linguagem humana, pois é o próprio discurso, oral ou escrito, de qualquer gênero e esfera da atividade humana, por excelência, o espaço do diálogo, da dialética da linguagem (porque contraditória) e da retórica, em sua natureza constitutiva. Não há discurso sem argumentatividade e não há retórica fora de discursos.

Para Souza (2008), as teses se apresentam como proposições, afirmativas ou negativas, sobre algo do mundo real. São ideias e posicionamentos que assumimos sobre o mundo e sobre as coisas que nele existem. São proposições, posicionamentos, que defendemos sobre diferentes temas ou problemas da realidade que se nos apresenta. Além disso, ao falar ou escrever, todo orador defende um ponto de vista, uma tese em seu discurso, por isso dizemos sempre que não há discurso sem argumentatividade nem há discurso sem interação entre orador e auditório, sem o dialogismo constitutivo da linguagem, sendo este o espaço em que se efetiva, por essência, a argumentatividade na linguagem.

Segundo Perelman e Olbrechts-Tyteca (2005), são quatro as técnicas argumentativas utilizadas, consciente ou inconscientemente pelos oradores, que têm como propósito construir a orientação argumentativa nos discursos. Elas são organizadas em quadro grupos, a saber: argumentos quase-lógicos, argumentos baseados na estrutura do real, argumentos que fundamentam a estrutura do real e os argumentos por dissociação das noções, sobre os quais faremos uma breve explanação.

Os Argumentos quase-lógicos, consoante os postulados de Perelman e OlbrechtsTyteca (2005, p. 219), são aqueles que, em certa medida, podem comparar-se a raciocínios formais, lógicos ou matemáticos, pois há a criação de um esquema formal que serve de base à construção do argumento, que, quando submetidos a operações de redução para a inserção de dados, tornam-se comparáveis, semelhantes e homogêneos. Os autores classificam como argumentos quase-lógicos a regra de justiça, que se fundamenta no igual tratamento a seres ou situações de uma mesma categoria; a retorsão que é feita usando o mesmo argumento do interlocutor; a definição, cuja escolha conceitual é fundamentada em discussão, no caso de haver consequência para o raciocínio; $o$ sacrifício, sistema de trocas, em que se sacrifica algo por determinado resultado; a comparação, confronto de realidades diferentes, para que elas sejam avaliadas umas em 
relação a outras; a reciprocidade, relação de simetria entre duas situações; a transitividade, relação entre um primeiro e segundo elementos e relação entre o segundo e um terceiro elementos, o que expressa uma relação entre o primeiro e o terceiro elementos; e a inclusão/divisão, que é a relação do todo e suas partes tratada sob dois aspectos: a inclusão das partes no todo e a divisão do todo em suas partes.

Já os argumentos baseados na estrutura do real não estão ligados à descrição objetiva dos fatos, mas sim às opiniões relativas a ele. Nas palavras de Perelman e Olbrechts-Tyteca (2005, p. 297):

Enquanto os argumentos quase-lógicos têm pretensão a certa validade em virtude de seu aspecto racional, derivado de relações mais ou menos estreita entre eles e certas fórmulas lógicas ou matemáticas, os argumentos fundamentados na estrutura do real valem-se dela para estabelecer uma solidariedade entre juízos admitidos e outros que se procura promover. (PERELMAN E OLBRECHTS-TYTECA, 2005, p. 297)

Para Perelman e Olbrechts-Tyteca, os argumentos baseados na estrutura do real são: o argumento pragmático, que é aquele baseado na apreciação de um ato, conforme suas consequências favoráveis ou desfavoráveis, transferindo valores entre elementos de uma cadeia causal; argumento do desperdício, que defende que ao iniciar uma obra deve-se ir até o final para não desperdiçar os sacrifícios já mobilizados; argumento pela superação, que consiste na possibilidade de ir sempre mais longe num determinado sentido, sem estabelecer limites nessa direção, o que gerará um crescimento contínuo de valor; argumento de autoridade, que busca fazer uso de palavras/opiniões de pessoa reconhecida para reforçar a tese defendida.

Existem ainda, como terceiro grupo das técnicas argumentativas, os argumentos que fundamentam a estrutura do real, estes subdivididos em duas categorias: a) fundamentado pelo caso particular que engloba os argumentos pelo exemplo que, baseados em um acordo preliminar entre o orador e auditório, são usados como possibilidade de gerar regras ou explicar fenômenos similares e também particulares; argumento pela ilustração, que "tem a função de reforçar a adesão a uma regra conhecida e aceita, fornecendo casos particulares que esclarecem o enunciado geral” (PERELMAN, OLBRECHTS-TYTECA, 2005, p. 407), e o argumento pelo modelo e antimodelo, quando um comportamento tido como modelo a ser seguido estimula uma ação, promovendo certa conduta, e o antimodelo, quando o comportamento permite afastar-se de determinada conduta; e b) o raciocínio por analogia, que pretende estabelecer relação de semelhança entre duas entidades, ganhando força neste o uso das metáforas.

Por fim, o grupo dos argumentos por dissociação de noções, diferem dos demais, pois, conforme Reboul (2004, p. 189), enquanto aqueles associam noções, estes dissociam noções em pares hierarquizados, como aparência/ realidade, meio/ fim etc. Essa dissociação objetiva suprimir incompatibilidades, tornando-a convincente e durável. São, portanto, essas as quatro grandes técnicas argumentativas, às quais estão vinculados dezenas de argumentos, que dão sustentação e orientação aos processos argumentativos, 
nos diferentes discursos orais e escritos. São, também, com base nessas categorias teóricas e analíticas da Nova Retórica que analisamos a seguir as respostas escritas em questionários, por professores surdos, aqui tratados como oradores de discursos sobre o ensino de LIBRAS e outros assuntos inerentes aos espaços da escola e da vida cotidiana de professores e de pessoas surdas.

\section{4) Análise da argumentação em Língua Portuguesa como segunda língua para usuários de LIBRAS}

Para a realização da pesquisa, trabalhamos com respostas dadas por dois surdos bilíngues residentes em diferentes cidades e que se destacam em suas comunidades por terem superados as dificuldades e terem concluído o ensino superior, bem como por atuarem no mercado de trabalho e terem reconhecimento profissional e social pelo que fazem. Nossas perguntas foram direcionadas justamente à vida escolar dos mesmos e foram feitas por escrito, em Língua Portuguesa, pois já sabíamos previamente que os dois eram bilíngues, e dominavam a modalidade escrita de Português como L2, em especial a leitura e de escrita.

A análise tem como foco aspectos do processo argumentativo dos discursos que subjazem às respostas dos professores bilíngues aos questionários aplicados. Observaremos, em especial, as teses defendidas, as técnicas argumentativas e os argumentos mobilizados por oradores/bilíngues para a construção da argumentação em suas respostas, levando-se em consideração que a maioria das pessoas surdas apresenta irregularidades morfossintáticas na escrita, devido à relação que fazem entre a estrutura de LIBRAS e a estrutura da escrita em Língua Portuguesa, utilizando-se de regras de uma língua para outra, o que pode levar a termos, na escrita em Português, por exemplo, algumas construções que seriam próprias das línguas de sinais.

No processo de codificação dos dados e de preservação da imagem dos professores colaboradores da pesquisa (surdos e bilíngues), para identificação dos discursos dos dois entrevistados utilizaremos PS1 para Professor Surdo 1 e PS2 para Professor Surdo 2.

$\mathrm{Na}$ análise dos discursos desses professores, observamos o uso de diferentes argumentos, com pontos de vista bem delimitados e teses defendidas sobre os assuntos sobre os quais tratavam as perguntas escritas nos questionários. Nesse artigo, trouxemos somente partes das respostas ao questionário, para ilustração e interpretação, em excertos que revelam processos argumentativos construídos, sobretudo, por argumentos baseados na estrutura do real, como passamos a analisar a partir desse momento. Além disso, optamos por fazer a análise da argumentação nos discursos de PS1 e de PS2, considerando alguns dos aspectos do processo argumentativo, que se apresentaram mais produtivos nas respostas dos dois professores bilíngues. 


\section{1) $O$ argumento pragmático}

Os argumentos pragmáticos compõem o grupo dos argumentos baseados na estrutura do real e estão relacionados às consequências possíveis em função de determinadas ações. Nesse caso, havendo um acordo entre os interlocutores sobre os motivos da ação. Logo a ênfase recai sobre os efeitos da ação realizada provocados em determinadas situações. Nos discursos analisados, constatamos a mobilização dessa técnica argumentativa nos discursos dos dois participantes. Percebemos também que entre a multiplicidade de causas que poderiam ter sido citadas os enunciadores optam por aquelas que mais interessam para os propósitos argumentativos, vejamos nos excertos a seguir:

\section{Excerto 1:}

[...] Difícil comunicação escola ninguém saber Libras, não ter intérprete, muito difícil, alguns amigos ajudar também atividades e trabalho [...]. (Colaborador PS1).

\section{Excerto 2:}

[...] era única surda tava muito difícil por que todos professores não sabem LIBRAS_L Lingua Brasileira de Sinais. para ensinava, pois tava sem interprete, nunca teve pois tive muito dificuldades os amigos ouvintes me ajudava neste período". (Colaborador PS2).

Para sustentar a tese de que a falta de intérprete na escola potencializou as dificuldades, os dois recorrem ao argumento pragmático fundamentando, portanto, a relação entre os dois acontecimentos, que expressam entre si uma relação de causa e consequência: grandes dificuldades de comunicação como consequência da falta de profissionais qualificados. Assim, constatamos que o fato de não haver intérprete de Libras foi a causa das maiores dificuldades na vida escolar de ambos. Vale ressaltar ainda que embora saibamos que a ausência do intérprete seja apenas uma das causas das dificuldades, os participantes a destacam como sendo fundamental. Consequentemente a presença desse intérprete é uma causa necessária, conforme argumentos utilizados por PS1 e PS2, para a facilitação da aprendizagem.

\section{2) Argumentos pela direção, superação e modelo}

O argumento da superação se apresentou como forte, na relação entre dificuldades cotidianas da vida de um surdo e desejo de vencer na vida pelo estudo. Esse argumento foi usado pelos dois participantes e está ligado à superação de obstáculos em situações adversas. A insatisfação com a situação que lhes é imposta desempenha um papel motor 
para que se atinja o ideal inacessível, que eles queiram superar os limites, as dificuldades que se impõem. O obstáculo transforma-se num meio para passar a um estágio superior, conforme podemos observar a seguir:

\section{Excerto 3:}

[...] Outro escola ABEL COELHO publica Médio $1^{\circ}, 2^{\circ}$ e $3^{\circ}$ estudar já terminar certificado, mas ter sim as vezes recuperação alguns $2^{\mathrm{a}}$ até $8^{\mathrm{a}}$ séries também Ensino Médio $2^{\circ}$ até $3^{\circ}$ anos. Difícil comunicação escola ninguém saber Libras, não ter intérprete, muito difícil, alguns amigos ajudar também atividades e trabalho. Mas terminar cada ano aprovado muito FELIZ porque estudar muito e conseguir. (Colaborador PS1).

Nesse excerto, PS1 traça seu percurso estudantil destacando as dificuldades de não ter intérprete de Libras, de ter passado por recuperações ao longo dos anos, entretanto, conclui o trecho dizendo-se feliz por ter conseguido aprovação, mesmo diante de todas as adversidades. Em outra parte do discurso, PS1 explica que "Mãe e pai estudar pouco vida, pai só $2^{a}$ série primário e mãe $4^{a}$ série, mas não desistir, sempre lutar. " Observamos, portanto, a mobilização do argumento por superação, não somente dele, mas dos pais também que, apesar de pouco estudo, seguiram na luta e nunca desistiram. Aqui também podemos perceber a mobilização do argumento pelo caso particular (argumento pelo modelo), em que os pais funcionaram para PS1 como modelos de perseverança e persistência.

Ainda podemos constatar o uso do argumento por superação no discurso de PS2, quando no excerto abaixo ela também descreve episódios de sua vida escolar trazendo quase que as mesmas dificuldades de PS1:

\section{Excerto 4:}

Ensino Médio, ingressei no Escola Estadual mesma coisa, só classe regular e eu única surda, sem intérpretes e também todos professores não sabem Libras, Nunca repeti. Tive muitas dificuldades, mas pode contar a ajuda de os amigos ouvintes que me foi muito importante neste período. Depois terminei estudo ensino médio. Tentei fazer vestibular consegui entrei faculdade curso de Pedagogia. Hoje trabalho no cargo Auxiliar de Biblioteca faz 5 anos No SESC. (Colaboradora PS2).

Para ratificar ainda mais a superação alcançada, PS2 apresenta, ao final do excerto, suas conquistas, ao terminar o curso superior, quando enfrentava dificuldades até para concluir a Educação Básica, ela superou as adversidades e alcançou a conclusão do Nível Superior. Ainda para ilustrar sua superação, PS2 apresenta-se como funcionária pública, aparecendo como uma espécie de premiação por suas conquistas em meio a tantas 
adversidades. Isso mostra que ela conquistou um crescimento contínuo de valor, indo sempre mais longe num certo sentido. Os argumentos baseados na estrutura do real, sobretudo pela direção, superação e pelo modelo ganharam força nos discursos e revelaram formas e aspectos motivadores da argumentação e da vida dos próprios professores.

\section{3) Argumento por autoridade e ainda pelo modelo}

Os argumentos por autoridade (às vezes, por modelo) ganham força na argumentação dos surdos e trazem à presença dos interlocutores recursos, imagens, nomes de respeito, que podem ser positivos e fortalecer a argumentação em curso.

\section{Excerto 5:}

Pai não quer ir escola, medo preconceito. Idade atrasado. Porque Eliene
irmã falar quer precisar ele vai ir escola aprender desenvolvimento
português, pai não quer muito sempre. Pai pensar medo acontecer cair
ou cosias também Bullyng. Não precisar besteira. Só precisar
importante aprender futuro vida ele. (Colaborador PS1).

Percebemos no excerto acima a mobilização por PS1 do argumento pelo modelo. Todavia, cabe salientar que esse argumento não fora utilizado por ele, mas há uma reprodução em discurso indireto do discurso do pai (autoridade para ele e também exemplo a ser seguido) que utilizou dessa técnica para sustentar a tese de que não era necessário que o filho frequentasse a escola “...Só precisar importante aprender futuro vida ele”. Frequentar a escola não seria algo favorável por diversos motivos, bastava que PS1 seguisse o modelo do pai, que também não frequentou a escola, e já aprenderia como ter um futuro na vida. Vale destacar que o modelo funciona mais do que como um exemplo, pois é dado como algo digno de imitação, sobretudo se esse modelo tem peso também como uma autoridade legítima e reconhecida pelo orador.

\section{4) Argumento pela ilustração}

O argumento pela ilustração é usado para reforçar a adesão dos interlocutores a partir de um dado exemplo, que pode ser real ou fictício. Para isso, a ilustração fornece casos particulares para esclarecem o geral, pois aumenta a presença na consciência do interlocutor. Assim, observamos a mobilização dessa técnica nos dois discursos, em PS1 e em PS2 


\section{Excerto 6:}

[...] escola particular $5^{\text {a }}$ série os alunos não querer trabalho junto, difícil, não ajudar mim nada, professores pouco ajuda mim, eu difícil ruim, professores ensino alunos ouvintes fácil, mas eu surdo ruim.

(Colaborador PS1).

\section{Excerto 7:}

[...] Acho que é muito importante o professor de Lingua Portuguesa saber Libras (Lingua Brasileira de Sinais) que se comunicam já meio Libras sentem dificuldades na hora de aprendera gramática da língua portuguesa principal o uso verbal de tempo o conhecimento dos professores é muito importante. (Colaboradora PS2).

Para revelar as dificuldades encontradas por ele na $5^{\text {a }}$ série, PS1 ilustra essa premissa por meio do relato (também funciona como um recurso argumentativo de presença) de uma história de que tanto os colegas quanto o próprio professor da $5^{\mathrm{a}}$ série o ajudaram pouco neste ano. Ele ainda traz certa justificativa ao final quando diz que o ensino do professor era fácil para os ouvintes, mas para ele na condição de surdo não era. Então, o orador parte do seu caso particular para ilustrar as dificuldades que são vivenciadas por todo o grupo de surdos. Esses argumentos por ilustração as dificuldades que são baseados na estrutura do real, em acontecimentos ou noções já reconhecidas e aceitas pelos interlocutores. A sala de aula se torna um ambiente hostil para os surdos devido ao fato de eles não compartilharem a mesma linguagem dos demais e quando não há a ajuda dos professores e colegas a situação se agrava ainda mais. Aqui surge, novamente, um argumento pragmático, pela relação de causa e efeito.

Por outro lado, PS2, quando argumenta em favor da tese de que os professores de Língua Portuguesa precisam saber Libras, usa o exemplo da dificuldade de se aprender o uso dos tempos verbais. Também parte da ilustração do caso particular, mas que denota uma dificuldade de todos os surdos, já que a estrutura morfossintática da LIBRAS difere da estrutura da Língua Portuguesa, portanto, em seu discurso, é importante o professor dominar as duas línguas para saber adaptá-las e se comunicar melhor na escola e socialmente.

\section{Considerações finais}

Nesse artigo, consideramos a argumentação como um processo intrínseco ao discurso, pois entendemos que todo locutor/orador possui um auditório particular para o qual irá desenvolver técnicas argumentativas, que se amparam em ideologias, valores, 
casos particulares, dentre outros elementos, que são mobilizados para estabelecer um contínuo em defesa de uma tese.

A análise retórico-argumentativa desses discursos de PS1 e PS2 revelam também que pessoas surdas, usuárias da Língua Portuguesa (LP) como segunda língua (L2), são capazes articular elementos diferentes do processo da argumentação e construir raciocínios verossímeis, com teses elaboradas e argumentos consistentes. Nesta pesquisa, buscamos mostrar que esses sujeitos/oradores utilizam técnicas argumentativas em busca de defender teses relacionadas a sua vida e a sua profissão, fazendo uso da Língua Portuguesa como L2, o que vem reforçar a pertinência do trabalho na educação, em todos os níveis, do ensino de LIBRAS para falantes do Português como língua materna (L1) e do ensino de Português como L2 para pessoas surdas, usuárias de LIBRAS.

Desse modo, por meio de discursos que subjazem às respostas a questionários, a análise argumentativa foi capaz de nos mostrar, com base em respostas dos dois sujeitos participantes, que usuários de LP como L2 constroem seu discurso estruturado, principalmente, nos argumentos fundamentados na estrutura do real, utilizando-se dos argumentos pragmático, argumento pela direção e superação, argumento de autoridade, argumento pelo modelo e argumento pela ilustração, em defesa de teses como a de que é necessário o ensino de LIBRAS no ensino regular, como forma de inclusão e de crescimento amplo do ensino e aprendizagem de línguas, tanto a portuguesa como a de sinais, como também eles defendem a tese de que é difícil e até doloroso estudar e frequentar escolas públicas no Brasil, sendo surdos, usuários de LIBRAS, considerando a fragilidade da formação dos professores que constituem os quadros docentes das escolas públicas, muitas vezes sem nenhum conhecimento técnico de língua de sinais, e que prejudica a formação e traz muitas dificuldades aos usuários de línguas de sinais.

Os resultados desse estudo também podem contribuir para os estudo s sobre argumentação em Língua Portuguesa como segunda língua de usuários de Libras, pois entendemos, com base nos resultados alcançados, serem necessárias pesquisas que revelem como surdos articulam elementos argumentativos quando fazem uso da LP como L2, para que possamos ter mecanismos também de ensinar argumentação a surdos, articulando as línguas essenciais a uma boa comunicação para eles. Esses professores surdos, colaboradores nessa pesquisa, também são sujeitos sociais que utilizam a línguas (LIBRAS e Português) como meio de interação social para exercer sua cidadania, buscando evolução e desenvolvimento linguístico e humano, ao mesmo tempo em que lutam para evitar opressão, discriminação e até exclusão sociais.

\section{Referências}

BRASIL. Ministério da Educação. Secretaria de Educação Especial. Lei no 10.436. 24 de abril de 2002. Dispõe sobre a Língua Brasileira de Sinais - LIBRAS e dá outras providências. 
Ministério da Educação. Secretaria de Educação Especial. Ensino de língua portuguesa para surdos: caminhos para a prática pedagógica. Vol. I e II. Brasília: MEC/SEESP, 2002.

FERNANDES, S. Educação de Surdos. 2a ed. Curitiba: IBPEX, 2011.

FIORIN, J. L. Argumentação. São Paulo: Contexto, 2015.

GOLDFELD, M. A criança surda: Linguagem e cognição numa perspectiva sóciointeracionista. $2^{\mathrm{a}}$ ed. São Paulo: Plexus Editora, 2002.

KOZLOWSKI, L. O Modelo Bilíngue/Bicultural na Educação do surdo: Distúrbios da Comunicação, São Paulo, v.7, n.2, p147-156,1995.

MAZZOTTA, M.J. S. Educação especial no Brasil: história e políticas públicas. 4.ed. São Paulo: Cortes, 2003.

PERELMAN, C; OLBRESCHTS - TYTECA. L. Tratado de argumentação: a nova retórica. Tradução GALVÃO, M. E. A. P. 2 ed. São Paulo: Martins Fontes, 2005.

PLANTIN, C. A argumentação: Christian Plantin. tradução Marcos Marciolino. - São Paulo: Parábola Editorial, 2008.

QUADROS, R. Políticas Linguísticas e educação de surdos em Santa Catarina: Espaço de negociações. Cadernos CEDES, Campinas, v.69, p. 141 - 162, 2006.

REBOUL, O. Introdução à retórica. Tradução Ivone Castilho Benedetti. São Paulo: Martins Fontes, 2004.

STUMPF, M. R. Práticas de Bilinguismo - relato de experiências. Educação Temática Digital, Campinas, v.7, n.2, p.285 - 291, 2006.

SOUZA, G. S. de. A argumentatividade na linguagem: uma análise do texto jornalístico no livro didático. In: GREGOLIN, M. do R. V. et all (orgs.). Análise do discurso: entornos do sentido. Araraquara/SP: Laboratório Editorial da UNESP, (2001).

SOUZA, G. S. de. O nordeste na mídia: um (des)encontro de sentidos. Araraquara, 2003. 403 p. Tese (Doutoramento em Linguística e Língua Portuguesa) - Faculdade de Ciências e Letras, Campus de Araraquara, Universidade Estadual Paulista "Júlio Mesquita Filho". 
SOUZA, G. S. de. Argumentação no discurso: questões conceituais. In: FREITAS,

Alessandra Cardozo de; RODRIGUES, Lílian de Oliveira; SAMPAIO, Maria Lúcia Pessoa (Orgs.). Linguagem, discurso e cultura: múltiplos objetos e abordagens. Pau dos Ferros: Queima Bucha, (2008).

SOUZA, G. S. de; COSTA, R. L.; BARBOSA JUNIOR, F. F. A argumentação em discursos sobre o ensino superior na UERN: sentidos que constituem o Campus de Pau dos Ferros. EID\&A - Revista Eletrônica de Estudos Integrados em Discurso e Argumentação, v. 02, p.63-75, 2012.

STROBEL, K. As imagens do outro sobre a cultura surda. Florianópolis: Editora da UFSC, 2008. 